\title{
Equivalent Dose Rate 1 Meter from Neuroendocrine Tumor Patients Exiting the Nuclear Medicine Department After Undergoing Imaging
}

\author{
Jules Zhang-Yin ${ }^{1,2}$, Anne-Sophie Dirand ${ }^{1}$, Myriam Sasanelli ${ }^{3}$, Gwenaelle Corrégé ${ }^{1}$, Aude Peudon ${ }^{3}$, Thierry Kiffel ${ }^{2}$, \\ Valérie Nataf ${ }^{4}$, Jérôme Clerc ${ }^{3}$, Françoise Montravers ${ }^{1,2}$, and Jean-Noël Talbot ${ }^{1,2}$ \\ ${ }^{I}$ Department of Nuclear Medicine, Hôpital Tenon, AP-HP, Paris, France; ${ }^{2}$ Université Pierre et Marie Curie, Paris, France; \\ ${ }^{3}$ Department of Nuclear Medicine, Hôpital Cochin, AP-HP, Paris, France; and ${ }^{4}$ Radiopharmacy, Hôpital Tenon, AP-HP, Paris
}

\begin{abstract}
123I-metaiodobenzylguanidine (MIBG) and ${ }^{111}$ In-pentetrotide SPECT have been used for functional imaging of neuroendocrine tumors (NETs) for the last 2 decades. More recently, PET/CT imaging with ${ }^{18} \mathrm{~F}-\mathrm{FDG},{ }^{18} \mathrm{~F}$-fluorodihydroxyphenylalanine (FDOPA), and ${ }^{68} \mathrm{Ga}$ somatostatin-receptor ligands in NETs has been expanding. A literature search could find no direct measurements of the dose rate from NET patients exiting the nuclear medicine department after undergoing PET/CT with ${ }^{18} \mathrm{~F}-\mathrm{FDOPA}$ or ${ }^{68} \mathrm{Ga}-\mathrm{DOTATOC}$, a somatostatin analog. Methods: We measured the dose rates from 93 NET patients on leaving the department after undergoing PET/CT or SPECT/CT in our centers. In total, 103 paired measurements of equivalent dose rate at $1 \mathrm{~m}$ (EDR-1m) from the sternum and urinary bladder were obtained. The detector faced the sternum or bladder and was $1 \mathrm{~m}$ away from and directly in front of the patient. The practice for exiting the department differed according to whether the patient had been referred for PET/CT or for SPECT/CT. PET/CT patients were discharged after imaging, whereas SPECT/CT patients left the department earlier, just after radiopharmaceutical injection. Results: The median administered activity was $122 \mathrm{MBq}$ in $53{ }^{68} \mathrm{Ga}$-DOTATOC PET/CT studies, $198 \mathrm{MBq}$ in $15{ }^{18} \mathrm{~F}$-FDOPA $\mathrm{PET} / \mathrm{CT}$ studies, and $176 \mathrm{MBq}$ in $13{ }^{18} \mathrm{~F}-\mathrm{FDG}$ PET/CT studies. The corresponding median EDR-1m was $4.8,9.5$, and $8.8 \mu \mathrm{Sv} / \mathrm{h}$, respectively, facing the sternum, and $5.1,10.1$, and $9.5 \mu \mathrm{Sv} / \mathrm{h}$, respectively, facing the bladder. The median administered activity was $170 \mathrm{MBq}$ in $12{ }^{111} \mathrm{In}$-pentetreotide SPECT/CT studies and $186 \mathrm{MBq}$ in 10 123/MIBG SPECT/CT studies. The corresponding median EDR- $1 \mathrm{~m}$ was 9.4 , and $4.9 \mu \mathrm{Sv} / \mathrm{h}$, respectively, at the level of the sternum, and 9.3 and $4.7 \mu \mathrm{Sv} / \mathrm{h}$, respectively, at the level of the bladder. The EDR-1m was less than $20 \mu \mathrm{Sv} / \mathrm{h}$ in all patients. Thus, when exiting the nuclear medicine department, the NET patients injected with ${ }^{68} \mathrm{Ga}$-DOTATOC or ${ }^{123}$ I MIBG emitted an average EDR-1m roughly half that of patients injected with other radiopharmaceuticals. This finding is a complementary argument for replacing SPECT by PET somatostatin-receptor imaging. Conclusion: Our current practice of allowing patients to exit after PET/CT imaging or just after SPECT radiopharmaceutical injection appears to be safe from a radiation protection point of view. Restrictive advice is unnecessary for NET patients being discharged from the department.
\end{abstract}

\footnotetext{
Received Dec. 7, 2016; revision accepted Jan. 2, 2017.

For correspondence or reprints contact: Jules Zhang-Yin, Department of Nuclear Medicine, Hôpital Tenon, AP-HP, 4 rue de la chine, Paris 75020 , France.

E-mail: juleszhangyin@gmail.com

Published online Feb. 16, 2017

COPYRIGHT (C 2017 by the Society of Nuclear Medicine and Molecular Imaging.
}

Key Words: radiation protection; dose rate; somatostatin receptorbased PET/CT; somatostatin receptor-based SPECT/CT; neuroendocrine tumors (NET)

J Nucl Med 2017; 58:1230-1235

DOI: 10.2967/jnumed.116.187138

\section{A}

mong the in vivo imaging modalities, diagnostic nuclear medicine has the major advantage of providing a functional, or biologic, approach. The radiopharmaceutical is administered in minute amounts that induce no adverse effects but nevertheless expose the patient, staff, and others near the patient to radiation during the hours after imaging. When uptake of the radiopharmaceutical by the target organs or lesions is rapid enough, the patient exits the nuclear medicine department after undergoing imaging. For some other examinations, in which the radiopharmaceutical has a long uptake phase, the patient exits the department just after receiving the radiopharmaceutical and returns later for imaging.

Public concern about radiation exposure is growing. To address this concern using actual measurements, we searched the literature for the equivalent dose rate at $1 \mathrm{~m}$ (EDR-1m) from the sternum or bladder of a standing patient at the moment of exiting the department after receiving a radiopharmaceutical. Few data in this domain have actually been published, and data on the less frequently used and most recently introduced radiopharmaceuticals are completely lacking. We thus undertook the present study, which measured the EDR-1m of patients exiting the department after receiving a radiopharmaceutical.

For logistic reasons, we limited the measurements to patients who had been referred for diagnostic nuclear medicine imaging because of a neuroendocrine tumor (NET). Although this condition is infrequent, functional nuclear medicine imaging plays a major role in the management of a large proportion of NET patients (1). Functional imaging of NETs is currently performed using either of two main techniques of diagnostic nuclear medicine: PET or SPECT (2). Several radiopharmaceuticals are available for these techniques, with the selection being made on a patient basis according to the aggressiveness and primary location of the NET (3). For PET imaging of NETs $(4,5)$, the most frequently used radiopharmaceuticals are the glucose analog ${ }^{18}$ F-FDG, the amino acid analog ${ }^{18} \mathrm{~F}$-fluorodihydroxyphenylalanine (FDOPA), and a ${ }^{68} \mathrm{Ga}$-labeled ligand of somatostatin receptors, such as ${ }^{68} \mathrm{Ga}$-DOTATOC. For SPECT imaging of NETs, 
the catecholamine analog ${ }^{123}$ I-metaiodobenzylguanidine (MIBG) and another ligand of somatostatin receptors, ${ }^{111}$ In-pentetreotide, have been used for decades (6). Therefore, nuclear imaging of NETs has characteristics that we considered appropriate for our purpose: a reasonable sample can represent the population of NET patients, a large proportion of NET patients are referred for nuclear medicine imaging, PET or SPECT for these patients can be performed with several different radiopharmaceuticals labeled with various radionuclides, and no or few data are available on the radiation emanating from NET patients after receiving these radiopharmaceuticals.

\section{MATERIALS AND METHODS}

\section{Patients and Radiopharmaceuticals}

The EDR-1m measurements were performed on all consecutive patients referred to us for nuclear medicine imaging of a proven or suspected NET who gave written consent to the use of their anonymized data for research purposes. PET/CT with ${ }^{68} \mathrm{Ga}$-DOTATOC, ${ }^{18} \mathrm{~F}$-FDOPA, or ${ }^{18} \mathrm{~F}$-FDG was performed at Tenon Hospital. SPECT/CT with ${ }^{111} \mathrm{In}-$ pentreotide or ${ }^{123} \mathrm{I}-\mathrm{MIBG}$ was performed at Cochin Hospital. Before being imaged with ${ }^{123}$ I-MIBG, patients underwent thyroid blockade, precluding any significant thyroid uptake that could interfere with the precocious sternal dose rate measurement.

In both centers, EDR-1m measurements were performed until the results for at least 10 patients were available for each radiopharmaceutical. All nuclear medicine examinations were performed according to the standard procedure of each department for each radiopharmaceutical (Table 1). The radiopharmaceuticals were registered and had a marketing authorization in France. The only exception was ${ }^{68} \mathrm{Ga}$ DOTATOC, the use of which was authorized by the French Medicine Agency (Agence Nationale de Sécurité du Médicament et Des Produits de Santé) on an individual basis (Autorisation Temporaire d'Use Nominative).

\section{Dose Rate Detectors}

The measurements were performed at Tenon Hospital and Cochin Hospital using two different dose rate detectors after they had been cross-calibrated. The detector used at Tenon Hospital was an identiFINDER (FLIR Systems) $\gamma$-spectrometer. This is an $\mathrm{NaI}(\mathrm{Tl})$ scintillation detector whose equivalent dose rate range $(0.01 \mu \mathrm{Sv} / \mathrm{h}-1 \mathrm{~Sv} / \mathrm{h})$ includes the values expected in this study and whose energy range (15-3,000 keV) includes the values of the main photonic rays of the radionuclides administered for NET imaging (7): $511-1,883 \mathrm{keV}$ for ${ }^{68} \mathrm{Ga}, 511 \mathrm{keV}$ for ${ }^{18} \mathrm{~F}, 23-245 \mathrm{keV}$ for ${ }^{111} \mathrm{In}$, and $27-529 \mathrm{keV}$ for ${ }^{123} \mathrm{I}$.

The detector used at Cochin Hospital was a PDS-100GN-ID Spectroscopic Personal Radiation Detector (Mirion Technologies) that also matches all the same criteria. The difference between dose rates measured simultaneously with the two detectors at $1 \mathrm{~m}$ from a ${ }^{51} \mathrm{Co}$ source corresponding to the expected dose rate range was less than $0.1 \mu \mathrm{Sv} / \mathrm{h}$.

\section{Timing of EDR-1m Measurements}

To maximize accuracy, a 1-m stick was used to define the distance between the patient and the detector. Two measurements were done: one with the detector facing the sternum and another facing the urinary bladder. The EDR-1m was corrected for the background of the same room in the absence of the patient; the typical background dose rate was $0.04-0.06 \mu \mathrm{Sv} / \mathrm{h}$.

Our aim was to determine the EDR-1m when the patient left the department: in the case of multiple imaging sessions after a single administration of the radiopharmaceutical, the measurements were taken only at the patient's first exit.

Thus, for PET/CT examinations, the EDR-1m was measured after image acquisition, approximately $1.5-2 \mathrm{~h}$ after injection of the radiopharmaceutical. The patients voided before the acquisition of the PET images but only rarely voided again afterward (i.e., just before the measurements). The SPECT examinations took place several hours after injection of the radiopharmaceutical; the EDR-1m was therefore measured a few minutes after injection, just before the patient left the department.

\section{Statistics}

Comparison of EDR-1m among the 5 radiopharmaceuticals was performed by ANOVA. When the hypothesis of equality of variance was rejected by the Levene test, ANOVA was replaced by the nonparametric

TABLE 1

Radiopharmaceuticals and Practical Options at Each Center

\begin{tabular}{|c|c|c|c|c|c|}
\hline Parameter & ${ }^{68} \mathrm{Ga}-\mathrm{DOTATOC}$ & ${ }^{18} \mathrm{~F}-\mathrm{FDOPA}$ & ${ }^{18} \mathrm{~F}-\mathrm{FDG}$ & $\begin{array}{c}{ }^{111} \mathrm{In}- \\
\text { pentetreotide }\end{array}$ & 123|-MIBG \\
\hline Hospital & Tenon & Tenon & Tenon & Cochin & Cochin \\
\hline Modality & PET/CT & $\mathrm{PET} / \mathrm{CT}$ & $\mathrm{PET} / \mathrm{CT}$ & SPECT/CT & SPECT/CT \\
\hline Radiopharmaceutical & $\begin{array}{l}{ }^{68} \mathrm{Ga}-\mathrm{DOTATOC} \\
\text { (lason) and } \\
\text { GalliaPharm } \\
\text { (Eckert \& Ziegler) }\end{array}$ & lasodopa (lason) & $\begin{array}{l}\text { Metatrace } \\
\text { (Siemens) or } \\
\text { Gluscan (AAA) }\end{array}$ & $\begin{array}{l}\text { Octreoscan } \\
\quad \text { (Mallinckrodt) }\end{array}$ & $\begin{array}{l}\text { 123/-MIBG } \\
\text { (Mallinckrodt) or } \\
\text { Adreview (GE } \\
\text { Healthcare) }\end{array}$ \\
\hline Physical half-life (min) & 68 & 110 & 110 & $4,032(2.8 d)$ & 792 (13.2 h) \\
\hline $\begin{array}{l}\text { Scheduled injected } \\
\text { activity }\end{array}$ & $1-2 \mathrm{MBq} / \mathrm{kg} \mathrm{BM}$ & 2.5-3.5 MBq/kg BM & 2-3 MBq/kg BM & $185 \mathrm{MBq}$ & $185 \mathrm{MBq}$ \\
\hline $\begin{array}{l}\text { Scheduled interval } \\
\text { between injection } \\
\text { and imaging (min) }\end{array}$ & $45-90$ & 10 (MTC) and 60 & $60-120$ & $1,440(24 \mathrm{~h})$ & $\begin{array}{r}240 \text { and } 1,440 \\
(4 \text { and } 24 \text { h) }\end{array}$ \\
\hline $\begin{array}{c}\text { Photonic ray for } \\
\text { imaging (keV) }\end{array}$ & 511 & 511 & 511 & 245 and 171 & 159 \\
\hline $\mathrm{BM}=$ body mass; $\mathrm{MTC}$ & $=$ medullary thyroid & ncer. & & & \\
\hline
\end{tabular}


TABLE 2

Patients, Imaging Characteristics, and EDR-1m According to Radiopharmaceutical

\begin{tabular}{|c|c|c|c|c|c|c|}
\hline Parameter & ${ }^{68} \mathrm{Ga}-\mathrm{DOTATOC}$ & ${ }^{18} \mathrm{~F}-\mathrm{FDOPA}$ & ${ }^{18} \mathrm{~F}-\mathrm{FDG}$ & $\begin{array}{c}111 / \mathrm{n}- \\
\text { pentetreotide }\end{array}$ & 123/-MIBG & Comparison \\
\hline Patients (n) & 53 & 15 & 13 & 12 & 10 & $\begin{array}{l}\chi^{2}: \text { NSD in sex } \\
\text { repartition }\end{array}$ \\
\hline Male & 29 & 6 & 8 & 6 & 3 & \\
\hline Female & 24 & 9 & 5 & 6 & 7 & \\
\hline Age $(y)$ & $\begin{array}{c}56.7 \pm 12.3 \\
58(30-76)\end{array}$ & $\begin{array}{c}60.9 \pm 12.1 \\
61(29-78)\end{array}$ & $\begin{array}{c}64.5 \pm 17.0 \\
66(37-89)\end{array}$ & $\begin{array}{c}62.1 \pm 12.6 \\
63(38-81)\end{array}$ & $\begin{array}{c}51.0 \pm 10.2 \\
53(30-65)\end{array}$ & ANOVA: NSD \\
\hline Body height (m) & $\begin{array}{c}1.70 \pm 0.09 \\
1.71(1.53-1.96)\end{array}$ & $\begin{array}{c}1.70 \pm 0.09 \\
1.67(1.57-1.83)\end{array}$ & $\begin{array}{c}1.66 \pm 0.08 \\
1.69(1.51-1.77)\end{array}$ & $\begin{array}{c}1.70 \pm 0.12 \\
1.72(1.45-1.86)\end{array}$ & $\begin{array}{c}1.68 \pm 0.10 \\
1.69(1.56-1.83)\end{array}$ & ANOVA: NSD \\
\hline Body mass (kg) & $\begin{array}{l}72.4 \pm 13.8 \\
71(49-105)\end{array}$ & $\begin{array}{c}72.3 \pm 13.5 \\
75(50-91)\end{array}$ & $\begin{array}{l}68.4 \pm 20.6 \\
60(39-120)\end{array}$ & $\begin{array}{l}72.7 \pm 13.7 \\
73.5(54-95)\end{array}$ & $\begin{array}{l}73.3 \pm 11.0 \\
76.5(58-88)\end{array}$ & ANOVA: NSD \\
\hline $\begin{array}{l}\text { Body mass } \\
\text { index }\left(\mathrm{kg} \cdot \mathrm{m}^{-2}\right)\end{array}$ & $\begin{array}{c}24.9 \pm 4.27 \\
24.5(17.3-37.1)\end{array}$ & $\begin{array}{c}24.6 \pm 4.27 \\
24.4(17.2-34.5)\end{array}$ & $\begin{array}{c}24.6 \pm 6.01 \\
23.9(15.2-38.7)\end{array}$ & $\begin{array}{c}25.1 \pm 3.79 \\
24.4(18.7-30.7)\end{array}$ & $\begin{array}{c}26.3 \pm 4.03 ; \\
25.3(21.3-33.6)\end{array}$ & ANOVA: NSD \\
\hline $\begin{array}{l}\text { Injected activity } \\
\text { (MBq) }\end{array}$ & $\begin{array}{c}121 \pm 23 \\
122(80-170)\end{array}$ & $\begin{array}{c}199 \pm 48 \\
198(97-262)\end{array}$ & $\begin{array}{c}176 \pm 56 \\
167(98-321)\end{array}$ & $\begin{array}{c}170 \pm 7 \\
170(158-179)\end{array}$ & $\begin{array}{c}186 \pm 5 \\
184(176-194)\end{array}$ & $\begin{array}{l}{ }^{68} \mathrm{Ga}-\mathrm{DOTATOC} \\
<\text { all others; } \\
\mathrm{KW}: P<< \\
0.001\end{array}$ \\
\hline $\begin{array}{l}\text { Injected activity } \\
\text { per kg body } \\
\text { mass (MBq/ } \\
\text { kg) }\end{array}$ & $\begin{array}{c}1.72 \pm 0.42 ; \\
1.77(0.89-2.80)\end{array}$ & $\begin{array}{c}2.74 \pm 0.42 ; \\
2.83(1.87-3.27)\end{array}$ & $\begin{array}{c}2.59 \pm 0.38 \\
2.51(2.23-3.81)\end{array}$ & $\begin{array}{c}2.41 \pm 0.48 \\
2.30(1.77-3.29)\end{array}$ & $\begin{array}{c}2.58 \pm 0.45 \\
2.43(2.00-3.27)\end{array}$ & $\begin{array}{l}{ }^{68} \text { Ga-DOTATOC } \\
<\text { all others; } \\
\text { ANOVA: } P< \\
0.001\end{array}$ \\
\hline $\begin{array}{l}\text { Interval between } \\
\text { injection and } \\
\text { EDR-1m } \\
\text { measurement } \\
\text { (min) }\end{array}$ & $\begin{array}{c}90 \pm 16 \\
87(66-126)\end{array}$ & $\begin{array}{c}114 \pm 14 \\
117(86-130)\end{array}$ & $\begin{array}{c}112 \pm 39 \\
95(82-220)\end{array}$ & $\begin{array}{c}6.2 \pm 3.5 \\
5(2-15)\end{array}$ & $\begin{array}{c}5.7 \pm 2.6 \\
5(3-10)\end{array}$ & $\begin{array}{l}\text { PENT \& }{ }^{123} \mathrm{I}- \\
\text { MIBG }<{ }^{68} \mathrm{Ga}- \\
\text { DOTATOC }< \\
{ }^{18} \mathrm{~F}-F D O P A \& \\
{ }^{18} \mathrm{~F}-\mathrm{FDG} ; \mathrm{KW}: \\
P<<0.001\end{array}$ \\
\hline $\begin{array}{l}\text { EDR-1m from } \\
\text { sternum } \\
(\mu \mathrm{Sv} / \mathrm{h})\end{array}$ & $\begin{array}{c}4.73 \pm 1.41 \\
4.75(2.10-9.10)\end{array}$ & $\begin{array}{c}9.76 \pm 3.61 \\
9.50(3.92-17.7)\end{array}$ & $\begin{array}{c}9.34 \pm 3.51 \\
8.80(3.50-18.8)\end{array}$ & $\begin{array}{c}9.56 \pm 0.93 \\
9.43(8.50-11.0)\end{array}$ & $\begin{array}{c}4.94 \pm 0.31 \\
4.89(4.45-5.49)\end{array}$ & $\begin{array}{l}{ }^{68} \mathrm{Ga} \text {-DOTATOC } \\
\text { \& }{ }^{123} \text { I-MIBG }< \\
\text { all others; KW: } \\
P<<0.001\end{array}$ \\
\hline $\begin{array}{l}\text { EDR-1m from } \\
\text { bladder } \\
(\mu \mathrm{Sv} / \mathrm{h})\end{array}$ & $\begin{array}{c}5.04 \pm 1.37 \\
5.10(2.13-8.20)\end{array}$ & $\begin{array}{c}10.2 \pm 3.20 \\
10.1(4.57-15.8)\end{array}$ & $\begin{array}{c}10.5 \pm 4.28 \\
9.50(3.80-21.2)\end{array}$ & $\begin{array}{c}9.21 \pm 1.31 ; \\
9.30(5.81-11.2)\end{array}$ & $\begin{array}{c}4.41 \pm 0.93 \\
4.68(2.80-5.65)\end{array}$ & $\begin{array}{l}{ }^{68} \mathrm{Ga}-\mathrm{DOTATOC} \\
\&^{123} \text {-MIBG }< \\
\text { all others; KW: } \\
P<<0.001\end{array}$ \\
\hline $\begin{array}{l}\text { EDR-1m from } \\
\text { sternum per } \\
\text { injected } \mathrm{MBq} \\
\text { (nSv/h/MBq) }\end{array}$ & $\begin{array}{c}39.4 \pm 10.7 \\
37.7(21.9-89.7)\end{array}$ & $\begin{array}{c}51.7 \pm 25.1 \\
45.5(25.0-116)\end{array}$ & $\begin{array}{c}54.4 \pm 13.8 \\
57.1(16.5-71.5)\end{array}$ & $\begin{array}{c}56.3 \pm 4.6 \\
55.5(50-64)\end{array}$ & $\begin{array}{c}26.6 \pm 1.5 \\
26.5(23.6-29.5)\end{array}$ & $\begin{array}{l}{ }^{123} \text { I-MIBG }< \\
{ }^{68} \mathrm{Ga}- \\
\text { DOTATOC \& } \\
{ }^{18} \text { F-FDOPA < } \\
{ }^{18} \text { F-FDG \& } \\
\text { PENT; KW: } \\
P<<0.001\end{array}$ \\
\hline $\begin{array}{l}\text { EDR-1m from } \\
\text { bladder per } \\
\text { injected } \mathrm{MBq} \\
(\mathrm{nSv} / \mathrm{h} / \mathrm{MBq})\end{array}$ & $\begin{array}{c}41.9 \pm 10.0 \\
41.0(25.4-88.5)\end{array}$ & $\begin{array}{c}54.0 \pm 23.0 \\
44.8(26.1-104)\end{array}$ & $\begin{array}{c}60.4 \pm 15.5 \\
62.1(17.9-82.9)\end{array}$ & $\begin{array}{c}54.3 \pm 7.3 \\
56.0(34.1-62.5)\end{array}$ & $\begin{array}{c}23.7 \pm 4.9 \\
25.0(15.3-29.1)\end{array}$ & $\begin{array}{l}\text { 123/-MIBG }< \\
{ }^{68} \mathrm{Ga}- \\
\text { DOTATOC }< \\
{ }^{18 F-F D O P A ~ \& ~} \\
\text { PENT < 18F- } \\
\text { FDG; KW: } \\
P<<0.001\end{array}$ \\
\hline
\end{tabular}

NSD = no significant difference; KW = Kruskal-Wallis test; PENT $={ }^{111} \mathrm{In}$-pentetreotide.

Data are mean $\pm S D$, or median followed by range in parentheses. 
Kruskal-Wallis test. The sternal EDR-1m measurements were compared with the bladder EDR-1m measurements using the $t$ test for paired values.

\section{RESULTS}

The EDR-1m measurements were performed from April to October 2016, ending when data were available for at least 10 patients for each radiopharmaceutical. In total, 103 paired measurements facing the sternum and the bladder were performed for 98 patients, since 4 patients underwent more than one examination: ${ }^{68} \mathrm{Ga}$-DOTATOC, ${ }^{18} \mathrm{~F}-\mathrm{FDG}$, and ${ }^{111} \mathrm{In}$-pentetreotide in 1 patient, ${ }^{68} \mathrm{Ga}$-DOTATOC and ${ }^{18} \mathrm{~F}$-FDOPA in 2 patients, and ${ }^{111} \mathrm{In}$-pentetreotide twice in 1 patient.

As expected, the choice of radiopharmaceutical differed according to the reason the patient had been referred for nuclear imaging. Of the $53{ }^{68} \mathrm{Ga}$-DOTATOC PET/CT studies, 19 were performed for staging or restaging of a pancreatic NET, 10 for staging or restaging of an intestinal or rectal NET, 6 for staging or restaging of a bronchial or thymic NET, 11 for characterization of a tumor suspected to be NET, and 7 for a NET of unknown primary. Of the $15{ }^{18} \mathrm{~F}$-FDOPA PET/CT studies, 12 were performed for staging or restaging of a NET of the ileum, 2 for a NET of unknown primary, and 1 for surveillance of medullary thyroid cancer. Of the $13{ }^{18} \mathrm{~F}-\mathrm{FDG}$ PET/ CT studies, 12 were performed for characterization of tumors, mainly lung nodules, suggestive of a NET and 1 for surveillance of an atypical NET of the thymus. Of the $12{ }^{111}$ In-pentetreotide SPECT/CT studies, 4 were performed for staging or restaging of an intestinal NET, 2 for staging or restaging of a pancreatic NET, 3 for characterization of tumors suggestive of a NET, 2 for paraneoplastic Cushing syndrome, and 1 for surveillance of an atypical NET of the thymus. Of the $10{ }^{123} \mathrm{I}$-MIBG SPECT/CT studies, 5 were performed for staging or restaging of a pheochromocytoma, 4 for characterization of lesions suspected of being pheochromocytoma, and 1 for paraneoplastic Cushing syndrome.

The main results of the study are reported in Table 2. There was no significant difference in patient characteristics (sex, age, body height, body weight, and body mass index) among examination types. The injected activity was significantly lower for ${ }^{68} \mathrm{Ga}$-DOTATOC than for any other radiopharmaceutical. The SD was smaller for SPECT tracers $\left({ }^{111} \mathrm{In}\right.$-pentetreotide and $\left.{ }^{123} \mathrm{I}-\mathrm{MIBG}\right)$, since the team at Cochin Hospital uses a fixed-activity approach for those radiopharmaceuticals.

As expected, the interval between injection and measurement was far shorter when the patient had been referred for SPECT/CT than when the patient had been referred for PET/CT. For PET/CT, the patient stayed in the department until the nuclear medicine specialist had reviewed the PET/CT images and allowed the patient to leave. The total stay in the department after injection was significantly shorter when ${ }^{68} \mathrm{Ga}$-DOTATOC was used than when either of the 2 fluorinated radiopharmaceuticals was used, although the image acquisition could begin at $60 \mathrm{~min}$ after injection for all three. The shorter stay for ${ }^{68} \mathrm{Ga}$-DOTATOC was probably due to the technical constraint related to the shorter physical half-life of ${ }^{68} \mathrm{Ga}$.

One main result is that the EDR-1m of patients injected with ${ }^{68} \mathrm{Ga}$-DOTATOC or ${ }^{123} \mathrm{I}-\mathrm{MIBG}$ was significantly lower than that with any of the other 3 radiopharmaceuticals.

Comparing the EDR-1m measurements for sternum and bladder in the same patient, we found that the latter was greater overall (paired $t$ test, $P<0.01$ ). There was a clear difference in bladder EDR-1m between the PET and SPECT tracers, with the measured value being higher for the PET tracers $(n=81, P<0.001)$ and lower, although not significantly so, for the SPECT tracers $(n=22, P=0.07)$.

As expected, there was a strong correlation between EDR-1m and injected activity (MBq or $\mathrm{MBq} / \mathrm{kg}$ ) (all $r>0.5, P<0.001)$.

TABLE 3

Studies Reporting Measurement of EDR-1m After Injection of ${ }^{18} \mathrm{~F}-\mathrm{FDG}$

\begin{tabular}{|c|c|c|c|c|}
\hline${ }^{18} \mathrm{~F}-\mathrm{FDG}$ & Present study & Fayad et al. (11) & Demir et al. (12) & Cronin et al. (13) \\
\hline Patients $(n)$ & 13 & 6 & 30 & 75 \\
\hline Injected activity (MBq) & & & 550 & $323 ; 297$ \\
\hline Mean \pm SD & $176 \pm 56$ & $241 \pm 33$ & & \\
\hline Range & $98-321$ & $130-311$ & & \\
\hline Median & 167 & & & \\
\hline $\begin{array}{l}\text { Time between injection and } \\
\text { EDR-1m measurement ( } \mathrm{min})\end{array}$ & 95 & 90 & & $113 ; 116$ \\
\hline Mean \pm SD & $112 \pm 39$ & & $117 \pm 11$ & \\
\hline Dose rate detector & identiFINDER & AT1123 (APVL Ingénierie) & ESP-2 (Eberline) & Series 1000 (Mini-Instruments) \\
\hline EDR-1m from sternum ( $\mu S v / h)$ & & & 50 & 14.7 \\
\hline Mean \pm SD & $9.34 \pm 3.51$ & $6.83 \pm 1.58$ & & \\
\hline Range & $3.50-18.8$ & & & $3.5-32$ \\
\hline Median & 8.80 & & & 14 \\
\hline $\begin{array}{l}\text { EDR-1m from sternum per } \\
\text { injected } \mathrm{MBq}(\mu \mathrm{Sv} / \mathrm{h} / \mathrm{MBq})\end{array}$ & & NA & 90 & 47 \\
\hline Mean \pm SD & $54.4 \pm 13.8$ & & & \\
\hline Range & $16.5-71.5$ & & & $13-120$ \\
\hline Median & 57.1 & & & 43 \\
\hline
\end{tabular}


TABLE 4

Studies Reporting Measurement of EDR-1m After Injection of ${ }^{111}$ In-Pentetreotide

\begin{tabular}{|c|c|c|c|c|}
\hline${ }^{111}$ In-pentetreotide & Present study & Fayad et al. (11) & Morán et al. (14) & Kurtaran et al. (15) \\
\hline Patients $(n)$ & 12 & 6 & 2 & 16 \\
\hline \multicolumn{5}{|l|}{ Injected activity (MBq) } \\
\hline Mean \pm SD & $170 \pm 7$ & $119 \pm 67$ & & $140 \pm 40$ \\
\hline Range & $158-179$ & $105-128$ & $200-220$ & \\
\hline $\begin{array}{l}\text { Time between injection and } \\
\text { EDR-1m measurement (min) }\end{array}$ & & 15 & & \\
\hline Mean \pm SD & $6.2 \pm 5$ & & & \\
\hline Range & & & $230-240$ & $10-20$ \\
\hline Dose rate detector & PDS-100GN-ID & AT1123 (APVL Ingénierie) & MiniTRACE y (Genitron) & LB 133 (Berthold Technologies) \\
\hline $\begin{array}{l}\text { EDR-1m from sternum } \\
\qquad(\mu \mathrm{Sv} / \mathrm{h})\end{array}$ & & & 9.5 & \\
\hline Mean \pm SD & $9.56 \pm 0.93$ & $5.5 \pm 0.51$ & & $2.86 \pm 1.22$ \\
\hline Range & $8.50-11.0$ & & & \\
\hline Median & 9.43 & & & \\
\hline $\begin{array}{l}\text { EDR-1m from sternum per } \\
\text { injected } \mathrm{MBq}(\mu \mathrm{Sv} / \mathrm{h} / \mathrm{MBq})\end{array}$ & & NA & 43 & NA \\
\hline Mean \pm SD & $54.3 \pm 7.3$ & & & \\
\hline
\end{tabular}

To test whether the lower EDR-1m with ${ }^{68} \mathrm{Ga}$-DOTATOC was a consequence simply of its having a lower injected activity than the other radiopharmaceuticals, we compared EDR-1m divided by injected activity (last 2 rows of Table 2). Per unit of injected activity, EDR-1m values were the lowest for ${ }^{123} \mathrm{I}-\mathrm{MIBG}$ and the next lowest for ${ }^{68} \mathrm{Ga}$-DOTATOC, with significantly lower EDR-1m values than those for ${ }^{111}$ In-pentetreotide, its SPECT alternative. In contrast, we observed no significant correlation between EDR-1m and body mass index $(r=0.1)$.

\section{DISCUSSION}

The present study found that EDR-1m was less than $20 \mu \mathrm{Sv} / \mathrm{h}$ in all patients, even though the highest values with ${ }^{18} \mathrm{~F}$-FDOPA or ${ }^{18} \mathrm{~F}$ FDG were close to that limit (Table 2). Actually, there is no constraint threshold for this dose rate in the European Union or anywhere else in the world. Furthermore, the few thresholds that have been proposed concerned patients leaving the nuclear medicine department after a therapeutic procedure, not after a diagnostic procedure. The lowest and most recently proposed limit was $20 \mu \mathrm{Sv} / \mathrm{h}(8)$. In 2010, the practical rules of the Heads of the European Radiological Protection Competent Authorities recommended a limit of $40 \mu \mathrm{Sv} / \mathrm{h}(9)$.

When exiting the department, patients injected with ${ }^{68} \mathrm{Ga}$-DOTATOC or ${ }^{123} \mathrm{I}-\mathrm{MIBG}$ delivered an average EDR-1m roughly half that delivered by patients injected with other radiopharmaceuticals. For an injected activity of the same order of magnitude, the shorter physical half-life of photons emitted by PET radiopharmaceuticals compensated for their higher energy because the patient had to remain longer before exiting. This finding is a complementary argument for replacing SPECT by PET for imaging of somatostatin receptors.

There were two major differences between PET and SPECT in routine practice. First, a fixed activity was used for patients referred for SPECT, in accord with the scheduled injected activities of the 2 SPECT radiopharmaceuticals in Table 1 and as revealed by the SDs

TABLE 5

Studies Reporting Measurement of EDR-1m After Injection of ${ }^{123}$ I-MIBG

\begin{tabular}{lcc}
\hline \multicolumn{1}{c}{ 123I-MIBG } & Present study & Ofluoglu et al. (10) \\
\hline Patients $(n)$ & 10 & 16 \\
Injected activity* $(\mathrm{MBq})$ & $186 \pm 5$ & $340 \pm 30$ \\
Time between injection and & $5.7 \pm 2.6^{*}$ & 10 \\
$\quad$ EDR-1m measurement $(\mathrm{min})$ & PDS-100GN-ID & LB 133 (Berthold Technologies) \\
Dose rate detector & Sternum: $4.94 \pm 0.31$; bladder: $4.41 \pm 0.93$ & $3.7 \pm 0.7$ \\
EDR-1m* $(\mu \mathrm{Sv} / \mathrm{h})$ & & \\
\hline & & \\
\hline
\end{tabular}


in Table 2. In contrast, the injected activity for PET radiopharmaceuticals was more variable, depending not only on patient body mass (in accord with the scheduled injected activities of the 3 PET radiopharmaceuticals in Table 1) but also on logistic constraints (the delivered activity in the multidose vial for fluorinated radiopharmaceuticals; the eluted activity from the ${ }^{68} \mathrm{Ge} /{ }^{68} \mathrm{Ga}$ generator and the labeling yield for ${ }^{68} \mathrm{Ga}$-DOTATOC).

The second major difference between PET and SPECT in routine practice is that patients who were referred for SPECT left the department a few minutes after injection and came back later for imaging, whereas patients referred for PET did not leave the department until after imaging, at least $1 \mathrm{~h}$ after injection (Table 2 ). This difference in the delay between injection and measurement explains why bladder EDR-1m was significantly greater than sternal EDR-1m for PET radiopharmaceuticals but not for SPECT radiopharmaceuticals. Because all 5 radiopharmaceuticals are excreted through the kidneys, urinary excretion and bladder accumulation of SPECT radiopharmaceuticals are just beginning when the patient exits the department, whereas for the PET radiopharmaceuticals, measured more than $1 \mathrm{~h}$ after injection, the bladder has become a radiation source. In this context, the variability of individual biologic half-lives between patients and the frequency of voiding enhance differences in individual equivalent dose rates.

Both factors (more homogeneous injected activity and shorter delay after injection) explain why the EDR-1m values had a much narrower range for SPECT radiopharmaceuticals than for PET radiopharmaceuticals (Table 2 ).

To the best of our knowledge as derived from an extensive bibliographical survey, no data have yet been published concerning EDR- $1 \mathrm{~m}$ at the time patients leave the nuclear medicine department after undergoing ${ }^{68} \mathrm{Ga}$-DOTATOC or ${ }^{18} \mathrm{~F}$-FDOPA PET/CT. This lack enhances the interest of the present ${ }^{68} \mathrm{Ga}$-DOTATOC data derived from a rather large sample $(n=53)$ representative of all NET indications, with a growing demand. The sample size was more limited for ${ }^{18} \mathrm{~F}$-FDOPA, but those data are probably the first of their kind. Very few data have been published concerning ${ }^{18} \mathrm{~F}-\mathrm{FDG}$ (Table 3), ${ }^{111}$ In-pentetreotide (Table 4), or ${ }^{123}$ I-MIBG (Table 5). Overall, all series are in accordance with the fact that the patient may leave the nuclear medicine department according to the current practice, that is, just after injection for ${ }^{111}$ In-pentetreotide or ${ }^{123}$ I-MIBG, without risk of exposing the public to excessive radiation. It is also clear that new developments in PET/CT scanners, particularly time-of-flight technology, have allowed a reduction in ${ }^{18}$ F-FDG injected activity and consequently a reduced EDR-1m (Table 3). In contrast, Demir et al. (12), who injected on average 3 times more ${ }^{18}$ F-FDG than we did, reported EDR-1m measurements of well above $20 \mu \mathrm{Sv} / \mathrm{h}$. Even when it was possible to normalize EDR-1m per megabecquerel of injected activity, a rather large variation in results between studies of similar design could be observed. One possible explanation is the small number of patients in most studies, including ours (apart from ${ }^{68} \mathrm{Ga}$-DOTATOC). Differences in individual functional processes lead to variability in EDR-1m enhanced by PET patients' lengthened stay in the department compared with SPECT patients. Nevertheless, this factor seems insufficient to explain a ratio of 3 in EDR-1m for ${ }^{111} \mathrm{In}-$ pentetreotide between the series of Kurtaran et al. (15) and ours: the waiting time is short and the injected activities are not in the same proportion. A similar question can be raised when comparing EDR-1m values after administration of ${ }^{123}$ I-MIBG; these values were significantly lower in the series of Ofluoglu et al. (10) than in ours, although the injected activity was almost twice greater. An alternative hypothesis involves the detectors themselves. Although our two detectors, produced by two different manufacturers, gave similar EDR-1m values, one cannot exclude the possibility that different dose rate detectors give discrepant results for the same measurements, particularly when the measurements have been performed over $14 \mathrm{y}$ or more.

\section{CONCLUSION}

When patients left the nuclear medicine department after undergoing ${ }^{68} \mathrm{Ga}$-DOTATOC PET/CT, their EDR-1m was lower than that after ${ }^{111}$ In-pentreotide injection, but the EDR-1m of patients who left after undergoing ${ }^{18} \mathrm{~F}$-FDOPA PET/CT was higher than that after ${ }^{123} \mathrm{I}-\mathrm{MIBG}$ injection. Nevertheless, EDR-1m was less than $20 \mu \mathrm{Sv} / \mathrm{h}$ in all patients for all 5 radiopharmaceuticals. Our nuclear medicine departments' current practice regarding exiting of NET patients after receipt of radiopharmaceuticals appears to be safe from a radiation protection viewpoint. There is no need to restrict patients from traveling by public or private transportation when authorizing them to leave the department after receiving nuclear medicine radiopharmaceuticals.

\section{DISCLOSURE}

No potential conflict of interest relevant to this article was reported.

\section{REFERENCES}

1. Kjaer A, Knigge U. Use of radioactive substances in diagnosis and treatment of neuroendocrine tumors. Scand J Gastroenterol. 2015;50:740-747.

2. Baumann T, Rottenburger C, Nicolas G, Wild D. Gastroenteropancreatic neuroendocrine tumours (GEP-NET): imaging and staging. Best Pract Res Clin Endocrinol Metab. 2016;30:45-57.

3. Montravers F, Grahek D, Kerrou K, et al. Can fluorodihydroxyphenylalanine PET replace somatostatin receptor scintigraphy in patients with digestive endocrine tumors? J Nucl Med. 2006;47:1455-1462.

4. Balogova S, Talbot JN, Nataf V, et al. ${ }^{18} \mathrm{~F}$-fluorodihydroxyphenylalanine vs other radiopharmaceuticals for imaging neuroendocrine tumours according to their type. Eur J Nucl Med Mol Imaging. 2013;40:943-966.

5. Prasad V, Ambrosini V, Alavi A, Fanti S, Baum RP. PET/CT in neuroendocrine tumors: evaluation of receptor status and metabolism. PET Clin. 2008;3:355379.

6. Modlin IM, Tang LH. Approaches to the diagnosis of gut neuroendocrine tumors: the last word (today). Gastroenterology. 1997;112:583-590.

7. Delacroix D, Guerre JP, Leblanc P. Guide Pratique: Radionucléides et Radioprotection. 3rd ed. Les Ulis, France: EDP Sciences; 1998.

8. Calais PJ, Turner JH. Radiation safety of outpatient ${ }^{177} \mathrm{Lu}$-octreotate radiopeptide therapy of neuroendocrine tumors. Ann Nucl Med. 2014;28:531-539.

9. ${ }^{131}$ I therapy: patient release criteria. Heads of the European Radiological Protection Competent Authorities website. http://www.herca.org/docstats/Annexe\% 20I_HERCA-OH_2011_0005_HERCA_Release\%20criteria\%2030062010.pdf. Published June 30, 2010. Accessed April 12, 2017.

10. Ofluoglu S, Preitfellner J, Fueger BJ, et al. Radiation exposure around patients after administration of 123-MIBG. Nuklearmedizin. 2002;41:221-223.

11. Fayad E, Maia S, Zilnus A, et al. Care continuity in post-scintigraphy period and radioactivity exposure of medical and technical staff. Med Nucl (Paris). 2015;39:380-385.

12. Demir M, Demir B, Sayman H, Sager S, Sabbir Ahmed A, Uslu I. Radiation protection for accompanying person and radiation workers in PET/CT. Radiat Prot Dosimetry. 2011;147:528-532.

13. Cronin B, Marsden PK, O'Doherty MJ. Are restrictions to behaviour of patients required following fluorine-18 fluorodeoxyglucose positron emission tomographic studies? Eur J Nucl Med. 1999;26:121-128.

14. Morán V, Prieto E, García-García B, et al. Radiation dose produced by patients during radiopharmaceutical incorporation in nuclear medicine diagnostic procedures. Rev Esp Med Nucl Imagen Mol. 2016;35:175-185.

15. Kurtaran A, Pfreitfellner J, Schaffarich P, et al. Radiation doses deriving from patients undergoing ${ }^{111}$ In-DTPA-D-phe-1-octreotide scintigraphy. Eur J Nucl Med. 1997;24:1298-1300. 